\title{
Nilai Literasi Kakawihan untuk Mengasuh Anak Usia Dini
}

\author{
Agus Ahmad Wakih \& Geri Syahril Sidik \\ Universitas Perjuangan \\ E-mail: agusahmadwakih@gmail.com; geri.syahril.unper@gmail.com
}

\begin{abstract}
How to cite (in APA Style): Wakih, A.A., \& Sidik, G.S.. (2020). Nilai literasi kakawihan untuk mengasuh anak usia dini. Jurnal Pendidikan Bahasa dan Sastra, Vol. 20(2), 177-184. doi: https://doi.org/10.17509/bs_jpbsp.v20i2.33058
\end{abstract}

Article History: (Received: 22 Jan 2020, Revised: 1 May 2020, Accepted: 1 July 2020)

Journal homepage: http://ejournal.upi.edu./index.php/BS_JPBSP

\begin{abstract}
Abstrak : Menurunnya percakapan anak-anak dengan menggunakan bahasa Sunda tentu memiliki penyebab yang beragam salah satunya menghilangnya pola pengasuhan orang tua, teringat bagaimana orang tua zaman dahulu dalam menyanyikan kakawihan. Kakawihan merupakan salah satu bentuk folklor lisan hasil kebudayaan lama masyarakat Sunda. Kakawihan didendangkan dalam permainan anak-anak masyarakat Sunda. Penelitian ini difokuskan pada nilai literasi dini yang terkandung di dalam kakawihan untuk mengasuh anak. Metode yang digunakan dalam penelitian ini yaitu metode kualitatif dengan melibatkan seorang budayawan atau tokoh literasi dan dosen di Kota Tasikmalaya. Data diambil dengan menggunakan wawancara semi terstruktur. Analisis data dilakukan dengan cara mereduksi, menyajikan data, dan menarik kesimpulan. Berdasarkan data yang sudah diperoleh lagu Ayun-ayun ambing yang memiliki nilai dan tujuan untuk menyuruh anaknya tidur sambil diayun-ayun pakai samping. Néléngnéngkung dinyanyikan untuk mépéndé atau menyuruh anak tidur atau untuk mengasuh anaknya yang masih bayi. Dug geura bobo dinyanyikan untuk bayi yang sudah agak besar. Dengkleung mengandung arti pekerjaan, harapan atau doa, dan tujuan. Ucang-ucang anggé yaitu lagu permainan sunda yang dinyanyikan oleh anak sambil ucang-ucangan mengayunkan kedua kakinya. Jampé-jampé harupat adalah sebuah mantra atau lagu jampi-jampi yang biasanya dinyanyikan atau diucapkan oleh orang tua baik untuk anaknya. Jampe bunghak beuteung digunakan sebagai mantra atau jampi-jampi untuk pengobatan.
\end{abstract}

Kata kunci: Nilai literasi dini; kakawihan; mengasuh anak

\section{Kakawihan Literacy Value for Early Childhood Care}

\begin{abstract}
The decline in children's conversations using the Sundanese language certainly has various causes, one of which is the disappearance of parental parenting patterns, remembering how ancient parents sang kakawihan. Kakawihan is a form of oral folklore resulting from the old culture of the Sundanese people. Kakawihan is sung in Sundanese children's games. This study focused on the value of early literacy contained in kakawihan for parenting. The method used in this research is a qualitative method by involving a humanist or literacy figure and a lecturer in the city of Tasikmalaya. Data were collected using semi-structured interviews. Data analysis was carried out by reducing, presenting data, and drawing conclusions. Based on the data that has been obtained, the song Ayun-ayun udder has a value and purpose to make her child sleep while rocking her side. Néléngnéngkung is sung for sending children to sleep or to care for their infant children. Dug geura bobo is sung for older babies. Dengkleung means work, hope or prayer, and purpose. Ucangucang anggé are Sundanese game songs sung by children while the words swing their legs. Jampéjampé harupat is a mantra or incantation song that is usually sung or chanted by both parents for their child. Jampé bunghake beuteung is used as a spell or incantation for healing.
\end{abstract}

Keywords: Early literacy values; kakawihan; parenting 


\section{PENDAHULUAN}

Masyarakat Indonesia dikenal sebagai masyarakat yang majemuk dengan keanekaragaman kebudayaan termasuk bahasa daerah sebagai identitas kebudayaan masing-masing etnis. Selain itu, Founding Father bangsa menyadari bahwa keragaman yang dimiliki bangsa merupakan realitas yang harus dijaga eksistensinya dalam persatuan dan kesatuan bangsa. Keragaman merupakan suatu kewajaran sejauh disadari dan dihayati keberadaannya sebagai sesuatu yang harus disikapi dengan toleransi. Kemajemukan ini tumbuh dan berkembang ratusan tahun lamanya sebagai warisan dari nenek moyang bangsa Indonesia (Lestari, 2015). Namun seiring perkembangan zaman, arus globalisasi yang menyusup pada setiap sendi kehidupan masyarakat Indonesia pelan-pelan menggerus kebudayaan setiap etnis termasuk nilai-nilai yang ada di dalamnya.

Salah satunya bahasa daerah sebagai identitas kebudayaan suatu daerah juga terkena dampak yang sama, temasuk bahasa Sunda di dalamnya. Sejauh ini, dari 700 lebih bahasa dari berbagai etnis yang ada di Indonesia, bahasa Sunda menjadi urutan nomor dua, dengan penutur terbanyak. Dalam Ethnologue: Language of The World (2005) dalam (Tondo, 2009) dikemukakan bahwa di Indonesia terdapat 742 bahasa, 737 bahasa di antaranya merupakan bahasa yang masih hidup atau masih digunakan oleh penuturnya. Pernyataan tersebut didukung oleh SIL (2001) dalam (Tondo, 2009) yaitu bahasa Jawa (75.200.000 penutur), Bahasa Sunda (27.000.000 penutur), bahasa Melayu (20.000.000 penutur), bahasa Madura (13.694.000 penutur), Bahasa Minangkabau (6.500.000 penutur), Bahasa Batak (5.150.000 penutur), bahasa Bugis (4.000.000 penutur), Bahasa Bali (3.800.000 penutur), bahasa Aceh (3.000.000 penutur), bahasa Sasak (2.100.000 penutur), bahasa Makasar (1.600.000 penutur), bahasa Lampung (1.500.000 penutur) dan Bahasa Rejang (1.000.000 penutur).

Dalam penelitian ini, peneliti akan memfokuskan pada bahasa Sunda sebagai bahasa daerah yang diteliti. Hal tersebut karena, masyarakat Sunda merupakan salah satu etnis yang berada di belahan bumi Indonesia. Sebagai salah satu etnis, masyarakat Sunda tentu saja memiliki beragam pranata kehidupan budaya tradisi yang merupakan simbol dan cerminan bagi kehidupan masyarakatnya (Mayakania, 2013). Tidak menutup kemungkinan penurunan jumlah penutur bahkan musnahnya bahasa Sunda sebagai bahasa daerah akan terjadi. Seperti yang dikemukakan oleh Baryadi (2014) bahwa pergeseran bahasa akhir-akhir ini banyak pihak yang menyatakan keprihatinannya bahwa ada sejumlah bahasa daerah di Indonesia yang sedang mengalami gejala pergeseran. Bahkan banyak pihak juga mengkhawatirkan ada sejumlah bahasa daerah yang akan punah. Pergeseran dan kepunahan bahasa daerah dikhawatirkan juga berakibat terkikis dan lenyapnya kekayaan budaya daerah sebab bahasa daerah merupakan perekam dan pengungkap unsurunsur budaya daerah. Salah satu contoh penurunan penggunaan bahasa daerah khususnya bahasa Sunda adalah semakin jarangnya anak-anak yang menggunakan bahasa tersebut dalam percakapan seharihari. Hal tersebut disebabkan oleh menghilangnya pola pengasuhan orang tua yang berakar pada budaya Sunda. Berbicara pola pengasuhan anak-anak yang berakar pada budaya Sunda, kita tentu akan teringat salah satu cara bagaimana orang tua zaman dahulu dan sebagian kecil saat ini, yang mengasuh anaknya dengan menyanyikan kakawihan.

Kakawihan merupakan salah satu bentuk folklor lisan hasil kebudayaan lama masyarakat Sunda. Kakawihan didendangkan dalam permainan anak-anak masyarakat Sunda. Saat mendendangkan kakawihan, anak-anak akan merasakan kesenangan atau kegembiraan, berbagi suka, saling berbagi perasaan, berkomunikasi, dan berinteraksi dengan teman-temannya. Namun di balik permainan itu, kakawihan pun digunakan untuk menyampaikan sebuah maksud dengan menggunakan bahasa sandi atau simbol bahasa yang hanya dimengerti oleh kelompoknya dan sulit untuk dipahami oleh orang lain di luar komunitasnya (Gloriani, 2013). Menurut Kamus Basa Sunda 
(Danadibrata, 2015) kawih berarti lagu sora jelema anu euneub pupubna, taya patokanana. Sementara kakawihan diartikan nyorakeun rира-rира kawih. Kawih berarti lagu atau suara orang yang tanpa patokan atau tanpa terikat dengan aturan pupuh. Sementara kakawihan adalah menyanyikan kawih. Kakawihan pada umumnya tidak dapat diketahui secara pasti kapan dan siapa penciptanya. Sebagaimana dikemukan oleh Umar Kayam (1991) bahwa kesenian tradisional atau kesenian rakyat bukan merupakan hasil kreativitas individu, tetapi tercipta secara anonim bersama dengan sifat kolektivitas masyarakat pendukungnya (Lestari \& Putra, 2019). Bentuk-bentuk seni juga bukanlah bentuk-bentuk kosong, tetapi bentuk-bentuk itu memikul tugas-tugas tertentu dalam membangun dan menata pengalaman manusiawi (Cassirer, 1982 dalam Mayakania, 2016).

Sehubungan dengan pemaparan di atas, kakawihan dapat digunakan orang tua dalam mengasuh anaknya. Terdapat beberapa gaya pengasuhan yang dilakukan oleh orang tua yaitu (1) Pengasuhan otoritarian yaitu gaya yang membatasi dan menghukum sehingga orang tua mendesak anak untuk mengikuti arahan mereka dan menghormati pekerjaan dan upaya mereka. (2) Pengasuhan otoritatif yaitu mendorong anak untuk mandiri namun masih menerapkan batas dan kendali pada tindakan mereka. (3) Pengasuhan yang mengabaikan yaitu gaya pengasuhan dimana orang tua tidak terlibat dalam kehidupan anak. (4) Pengasuhan menuruti yaitu gaya pengasuhan dimana orang tua sangat terlibat dengan anak, namun tidak terlalu menuntut atau mengotrol mereka (Baumrind, 1971 dalam Santrok, 2007). Setiap keluarga melakukan gaya pengasuhan yang berbeda, namun ketika seluruh anggota keluarga menghabiskan waktu bersama, mereka menciptakan sebuah identitas bersama sekaligus menyimpan kenangan yang indah (Byron, 2009). Sehingga pengenalan kakawihan pada anak dapat dilakukan orang tua ketika mengasuh anak yang dapat menciptakan kenangan bagi anak dan anak akan mengingat kakawihan apa yang pernah diberikan orang tuanya. Oleh karena itu, penelitian ini difokuskan terhadap nilai-nilai apa saja yang terkandung dalam kakawihan yang digunakan orang tua untuk mengasuh anaknya.

\section{METODE}

Metode yang digunakan dalam penelitian ini yaitu metode kualitatif. Metode penelitian kualitatif adalah metode yang tepat digunakan dalam penelitian ini, karena penelitian kualitatif dapat membantu para peneliti untuk mengakses pemikiran dan perasaan peserta penelitian, yang dapat memungkinkan pengembangan pemahaman tentang makna yang orang anggap berasal dari pengalaman mereka (Sutton \& Zubin, 2015). Untuk belajar dari pengalaman orang lain, perlu dipahami bagaimana pengalaman itu terjadi dan tindakan seperti apa yang dilakukan orang yang terlibat (Crescentini \& Mainardi, 2009). Metode kualitatif digunakan untuk menjawab pertanyaan tentang pengalaman, makna dan perspektif, paling sering dari sudut pandang partisipan (Hammarberg et al., 2016). Sehingga metode kualitatif tepat digunakan dalam penelitian ini, agar memperoleh data yang diinginkan oleh peneliti yaitu berupa nilai kakawihan untuk mengasuh anak usia dini.

\section{Partisipan}

Penelitian ini melibatkan 2 orang yaitu yang pertama SB seorang tokoh Terbang Gebes Group Pusparahayu Puspabyang, dan yang kedua adalah DA seorang dosen bahasa Sunda di salah satu Universitas di Tasikmalaya. Partisipan tersebut dipilih, karena dianggap mampu memberikan informasi perihal nilai kakawihan dalam mengasuh anak usia dini.

\section{Teknik Pengumpulan Data}

Data diperoleh dengan melakukan wawancara kepada partisipan. Wawancara dalam penelitian kualitatif menggunakan wawancara terbuka yang para partisipannya tahu bahwa mereka sedang di wawancarai dan mengetahui apa maksud dan tujuan wawancara itu (Moleong, 1988). Jenis wawancara yang digunakan adalah wawancara semi terstruktur. Pada wawancara ini interviewer atau pewawancara membuat 
garis besar pokok-pokok pembicaraan, namun dalam pelaksanaannya pewawancara mengajukan pertanyaan secara bebas (Satori \& Komariah, 2009).

Setelah itu peneliti melakukan analisis dengan langkah-langkah: (a) mereduksi data yaitu serangkaian proses kegiatan yang tak terpisah dari analisis. Kegiatan reduksi data diantaranya meliputi pemilihan, penyederhanaan, memfokuskan, dan mentransformasi data yang diperoleh. (b) menyajikan data yaitu menyusun informasiinformasi secara runtut dan jelas yang memungkinkan dapat digunakan peneliti sebagai dasar dalam pengambilan suatu kesimpulan. (c) menarik kesimpulan yaitu memberikan penjelasan makna data yang telah disajikan.

\section{Analisis Data}

Grounded theory adalah teknik analisis data yang digunakan dalam penelitian ini, karena dengan grounded theory peneliti bisa memperoleh data yang kaya sehingga informasi akan melimpah. Untuk menganalisis data, desain format grounded theory menurut Bungin (2007) antara lain: Tahap 1 berupa observasi pendahuluan yaitu menemukan tema-tema pokok pilihan, menemukan Gatekeepers, dan menemukan gambaran umum tentang alur penelitian; Tahap 2 berupa pengumpulan data yaitu menemukan informan, mewawancara dan mengobservasi serta membuat catatan harian, menemukan informan baru, mengembangkan strategi wawancara dan observasi, menggunakan triangulasi untuk menemukan kebenaran data, dan terusmenerus membuat catatan harian, dan; Tahap 3 berupa pengumpulan data lanjutan yaitu merevisi draf laporan penelitian, menemukaan kekurangn data dan informasi, membuang informasi yang tidak penting, menemukan informan baru, terus menerus menggunakan triangulasi, terus menerus membuat catatan harian baru, memutuskan untuk menghentikan penelitian, mengembangkan draf laporan menjadi rancangan laporan akhir, dan peneliti meninggalkan lokasi penelitian.

\section{HASIL DAN PEMBAHASAN}

Melantunkan kakawihan merupakan salah satu cara agar budaya sunda tidak tertelan oleh zaman, dan tetap menjadi bagian dari kehidupan masyarakat. Setiap kakawihan yang ditembangkan tentunya memiliki nilai dan tujuan tertentu. Salah satunya kawih kaulinan barudak lebih banyak mengandung nilai yang termasuk dalam budaya masyarakat Sunda, dahulu memiliki ciri khas tradisi dalam tata asuh dan tata didik bagi anakanaknya. Tata asuh dan tata didik ini diajarkan tidak secara formal, melainkan disajikan dalam pola permainan yang sesuai dan dibentuk dengan ciri kehidupan kesehariannya, salah satunya yakni melalui kakawihan.

Dimulai sejak bayi biasanya orang tua selalu memiliki kawih yang dihariringkan saat mengasuh anaknya. Misal saat orang tua mépépéndé' (menyuruh tidur), seorang ibu dengan penuh kasih sayangnya menidurkan anaknya dengan diéyong sambil melantunkan kawih Ayun Ambing. Jika bayi sudah agak besar kawih yang dinyanyikan biasanya berjudul Dug Gera Bobo. Nyanyian tersebut pada praktiknya diiringi dengan elusan tangan, kecup kening atau meniup ubunubun bayi. Ketika si bayi sudah menginjak umur sembilan bulan lebih, umumnya ia dapat merangkak dan duduk. Pada usia ini, anak akan disuruh duduk di ujung kaki yang menggantung, kedua tangan si anak dipegang, kemudian orang tua akan menyanyikan kawih Ucang-ucang anggé. Permainan Ucang-ucang anggé ini lazimnya dilakukan oleh bapak.

Ketika si anak mulai belajar jalan, kedua orang tua (ayah dan ibu) duduk berhadapan dengan jarak kira-kira dua meter, si anak disuruh berjalan dari arah ayahnya menuju ibunya dan terus dilakukan bolakbalik. Si ibu akan menangkap (nyanggap) si anak dan membalikkan badannya agar menuju ayahnya. Hal itu terus dilakukan berkali-kali. Permainan ini dilakukan tanpa diiringi dengan nyanyian, atau dengan nyanyian ning nang ning eu ning nang ning eu. Apabila si anak jatuh, maka orang tuanya akan segera memeluk anaknya sambil mengusap bagian badan yang dianggap sakit 
oleh anak sambil menyanyikan Jampé-jampé Harupat. Setiap kawih yang didendangkan tersebut memiliki nilai yang tidak tertulis seperti manusia tidak boleh mudah putus asa, manusia harus rendah hati, manusia harus mampu hidup dengan baik di lingkungannya, manusia harus gigih, manusia harus menjauhi dan tidak melakukan keburukan dalam hidupnya.

Oleh karena itu, setiap kakawihan yang dinyanyikan memiliki arti dan makna, seperti yang diungkapkan oleh responden penelitian yang menjelaskan mengenai nilai yang terkandung dalam setiap kakawihan berikut.

a. Ayun-ayun ambing

Ayun ambing ayun ambing

Diayun-ayun ku samping

Kawih ayun ambing di atas memiliki arti dan tujuan untuk menyuruh anaknya tidur. Zaman dulu khususnya orang Sunda tak asing dengan kata ayun ambing. Ketika orang tua menyuruh anaknya tidur, dan anaknya itu di ayun-ayun pakai samping orang tua pasti akan menembangkan kawih ini. Orang tua akan menidurkan anaknya dengan penuh kasih sayang sampai anak terlelap. Lagu ayu ambing menggambarkan aktivitas seorang ibu yang sedang meninabobokan dan menggendong anaknya.

Ayun Ambing dalam pengertian dan filosofisnya adalah:

Menimang anak orok dalam artian untuk menidurkan di pangkuan bapak, ibu, atau kakak baik dengan menggunakan samping (aisan) atau lengan sebagai penyanggah anak kecilnya. Maksud yang terkandung tiada lain adalah:

1. Untuk menyatukan rasa batin, kasih sayang melalui kawih, kakawihan atau lagu dengan genre (Sundanis atau Arab) sehingga akan nampak chemistry rasa diantara keduanya antara yang ditimang dan yang menimangnya.

2. Untuk mengistirahatkan raga tubuh dari kelelahan kreativitas anak/orok setelah kemungkinan" berpindah dari satu pangkuan ke pangkuan lain" akhirnya badan terasa nyeri, linu, atau pegal. Maka dengan ditimang si penimang mengurut atau mengelus dengan jari-jari tangannya kepunggung anak/orok yang ditimangnya.

3. Ayun-ayun ambing yang memiliki nilai dan tujuan untuk menyuruh anaknya tidur sambil diayun-ayun pakai samping (merasa damai).

b. Néléngnéngkung

Néléngnéngkung- néléngnéngkung

Geura gedé geura jangkung

Geura sakola ka Bandung

Geura makayakeun indung

Seperti halnya kawih ayun-ayun ambing, néléngnéngkung juga biasanya dinyanyikan untuk mépéndé atau menyuruh anak tidur atau untuk mengasuh anaknya yang masih bayi. Lagu ini menceritakan harapan dan doa yang dilantunkan oleh penutur atau ibu untuk anaknya agar anaknya tumbuh sehat, meraih ilmu yang banyak dan mampu membahagiakan orang tuanya. Lagu ini menceritakan harapan dan doa yang dilantunkan oleh penutur atau ibu untuk anaknya. Hal tersebut dapat di lihat dari arti liriknya yaitu geura gedé geura jangkung artinya cepat besar cepat tinggi, geura sakola ka Bandung artinya agar dapat bersekolah di Bandung, dan geura makayakeun indung artinya agar dapat membahagiakan atau berterimakasih kepada ibu.

c. Dug geura Bobo

Dug geura bobo

Disampakekeun pais bogo

Dug geura saré

Disampakkeun pais lélé

Kawih ini biasanya dinyanyikan untuk bayi yang sudah agak besar. Sama seperti halnya ayun ambing dan néléngnéngkung, lagu ini dinyanyikan untuk menidurkan bayi. Akan tetapi, 
kawih ini memiliki tujuan orang tua menidurkan bayinya dengan lebih memanjakannya. Seperti yang tertera dalam liriknya dug geura bobo yang artinya cepatlah tidur. Nyanyian tersebut pada praktiknya diiringi dengan elusan tangan, kecup kening atau meniup ubunubun bayi. Namun bedanya dengan kawih meninabobokan anak yang lain, disini terdapat kalimat disampakkeun pais bogo dan disampakkeun pais lélé, yang artinya akan disediakan pepes ikan bogo dan ikan lélé. Hal tersebut menunjukan bahwa ketika anak cepat tidur maka akan disediakan makanan enak seperti yang sudah dijelaskan diatas.

\section{d. Dengkleung}

Dengkleung déngdék.

Buah kopi raranggeuyan

Engkeun budak déwék.

Ulab pati diheureuyan

Lagu dengkleung déngdék ini terdiri dari sampiran dan isi yaitu berpola seperti pantun. Lagu ini berisi penegasan dengan cara menyembunyikan maksud yang sebenarnya. Awalnya lagu ini diciptakan untuk pemerintah kolonial Belanda akan tetapi tidak ditampilkan secara terang-terangan. Selain itu, lagu ini mengandung pekerjaan, harapan atau doa, dan tujuan yang lahir sebagai ancaman kepada orang lain agar tidak mengganggu sesuatu yang berharga milik penutur. Seperti yang tercantum dalam liriknya engkeun budak déwék ulah pati diheureuyan yang artinya jangan ganggu anak saya. Namun sama seperti lagu sebelumnya, lagu ini juga digunakan untuk meninabobokan anak.

e. Ucang-ucang anggé

Ucang-ucang anggé

Mulung muncang ka papanggé

Digogog ku anjing gedé

Anjing gedé nu ki lebé

Anjing leutik nu ki santri

Ari gog-gog cungungung
Lagu ucang-ucang angge di atas memiliki arti sebagai berikut.

Mengayun-ayunkan kaki

Memungut kemiri ke pintu pagar kebun

Di gonggong oleh anjing besar

Anjing besar punya penghulu

Anjing kecil punya ki santri

Tiba-tiba menggonggong cungungung

Lagu ucang-ucang anggé yaitu lagu permainan sunda yang dinyanyikan oleh orang tua sambil ucang-ucangan mengayunkan kedua kakinya duduk dikursi, kakinya diayun-ayunkan ke depan atau belakang, dengan anak (biasanya yang lebih kecil) duduk di atas kaki tersebut. Permainan ini dapat dilakukan antara adik dan kakak, anak dan ibu, atau anak dan ayah, akan tetapi biasanya dilakukan antara anak dan bapak. Lagu ucang-ucang angge bertujuan agar anak merasa senang, dengan lagu ini anak akan merasakan kedekatan dan kehangatan hubungan antara anak dan keluarganya. Ketika anak sudah memiliki chemistry dengan keluarganya, maka anak akan merasa saling memiliki. Hal tersebut karena lingkungan keluarga adalah lingkungan mikro atau lingkungan yang paling dekat dengan anak dan melakukan interaksi secara terus-menerus sehingga akan mempengaruhi perkembangan anak (Sardjunani, 2006). Hal tersebut karena, anak dengan keluarga terlibat dalam interaksi tatap muka, kontak pribadi terdekat yang dilakukan secara langsung (Graves \& Sheldon, 2018). Sehingga kawih ucang-ucang angge dapat dijadikan media agar orang tua dan anaknya memiliki kedekatan secara naluri.

Kakawihan ucang-ucang angge dapat menjadi cara untuk membuat anak dan orang tua memiliki hubungan yang erat. Hubungan yang baik antara anak dan orang tua akan berdampak baik bagi anak salah satunya untuk Pendidikan anak. Keterlibatan orang tua dalam pendidikan anak usia dini memberikan 
dampak yang positif sehingga pendidikan dapat dilakukan sesuai dengan perkembangan anak (Morrison, Storey \& Zhang, 2011). Oleh karena itu, keterlibatan peran orang tua dalam pendidikan adalah sebuah investasi yang dilakukan untuk mendukung pendidikan anak serta memberikan peran penting dalam perkembangan anak (Calzada et al., 2014). Hal tersebut, menunjukan bahwa kawih ucang-ucang angge tidak hanya untuk didendangkan, tetapi memiliki tujuan dalam penyampaiannya.

\section{f. Jampé-jampé harupat}

Jampé-jampé harupat

Geura gedé geura lumpat

Jampé-jampé harupat adalah sebuah mantra atau lagu jampi-jampi yang biasanya dinyanyikan atau diucapkan oleh orang tua baik untuk anaknya ataupun untuk cucunya yang masih bayi atau balita. Mantra ini mengandung motivasi supaya anak kuat menghadapi segala sesuatu yang menimpanya. Selain itu juga, mantra ini berisi doa supaya tumbuh dan berkembang dengan baik. Seperti arti liriknya jampé-jampé harupat artinya jampi-jampi, dan geura gedé geura lumpat artinya cepat besar cepat lari. Dari arti lirik tersebut kita tahu bahwa ketika ibunya menyanyikan lagu ini, ibunya memiliki harapan untuk anaknya di kemudian hari. Zaman dulu, orang tua percaya bahwa ketika anaknya dinyanyikan lagu ini secara rutin maka akan menjadi sugesti yang baik bagi perkembangan dan pertumbuhan anak. Biasanya orang tua menyanyikan ini sambil mengusap kepala anaknya sampai anak tertidur lelap.

g. Jampé Beunghak Beuteung

Cakakak dileuweung

Injuk talina

Dibakan dibeuneung

Hitut jadina
Lagu ini digunakan sebagai mantra atau jampi-jampi untuk pengobatan. Kegiatan ini dilakukan kepada anak-anak Zaman dulu, lagu ini dinyanyikan untuk mengobati orang yang sakit, salah satunya sakit perut. Ketika lagu ini dinyanyikan biasanya orang yang mengobati memenfaatkan obat dari alam yaitu digunakannya daun-daun untuk mengobati perut kembung. Obat alam atau dedauan yang sering digunakan yaitu daun kahitutan (artinya daun kentut), daun jambu, daun wera, dan daun kangkung bandung, atau bisa juga jampi tersebut disertai dengan menggosokan daun eurih ke perut yang sakit. Kegiatan ini biasanya dilakukan kepada anakanak yang merasa perutnya kembung. Ketika orang tua atau orang yang lebih dewasa menjampikan jampé beunghak beuteung ini, dengan penuh harapan seorang anak akan sembuh dari sakit perutnya.

Penjelasan setiap kakawihan diatas dapat kita ketahui bahwa terdapat maksud, doa, harapan yang disampaikan dalam setiap lirik kakawihan tersebut. Setiap kakawihan memiliki maksud yang berbeda, akan tetapi terdapat tujuan yang bermakna bagi setiap pendengarnya. Dari hasil penelitian tersebut, dapat dipahami bahwa setiap peninggalan budaya nenek moyang kita harus dilestarikan, sekecil apapun budaya tersebut tentunya akan memiliki nilai literasi yang bermakna khususnya mengenai peran orang tua dalam mengasuh anaknya.

\section{SIMPULAN}

Masyarakat Sunda adalah sebuah etnis yang berada di belahan bumi Indonesia. Sebagai salah satu etnis, masyarakat Sunda tentu saja memiliki beragam pranata kehidupan budaya tradisi yang merupakan simbol dan cerminan bagi kehidupan masyarakatnya salah satunya yaitu kakawihan. Kawih berarti lagu atau suara orang yang tanpa patokan atau tanpa terikat dengan aturan pupuh. Sementara kakawihan adalah menyanyikan kawih. Setiap kakawihan yang ditembangkan tentunya memiliki nilai dan tujuan tertentu. 


\section{UCAPAN TERIMA KASIH}

Peneliti mengucapkan terima kasih kepada pimpinan, seluruh dosen, staff pegawai, dan responden penelitian di Universitas Perjuangan yang telah memberikan dukungan moril, dan materil sehingga penelitian ini dapat diselesaikan dan diperoleh data sesuai dengan yang diharapkan.

\section{DAFTAR RUJUKAN}

Baryadi, I. P. (2014). Pengembangan 'Dwibahasawan yang Seimbang'untuk Mempertahankan Bahasa-bahasa Daerah di Indonesia. In I. Praptomo Baryadi dan Musdalipah (Editor). Bahasa Daerah: Kondisi dan Upaya Pemertahanannya (Prosiding). Penerbit Balai Bahasa Provinsi Kalimantan Selatan bekerja sama dengan Penerbit FAMILIA, 25-40.

Bungin, B. (2007). Penelitian Kualitatif. Jakarta: Prenada Media Grup.

Byron, T. (2009). Ensiklopedia perkembangan anak. Jakarta: Erlangga.

Calzada, E. J., Huang, K. Y., Hernandez, M., Soriano, E., Acra, C. F., DawsonMcClure, S., ... \& Brotman, L. (2015). Family and teacher characteristics as predictors of parent involvement in education during early childhood among Afro-Caribbean and Latino immigrant families. Urban Education, 50(7), 870-896.

Crescentini, A., \& Mainardi, G. (2009). Qualitative research articles: guidelines, suggestions and needs. Journal of workplace learning, (21)5, 431- 439.

Danadibrata, R.A. (2015). Kamus Bahasa Sunda. Bandumg. Kiblat Buku Utama.

Gloriani, Y. (2013). Kajian Nilai-Nilai Sosial dan Budaya pada Kakawihan Kaulinan Barudak Lembur serta Implementasinya dalam Pembelajaran Bahasa dan Sastra Indonesia Berbasis Multikultural. Lokabasa, 4(2), 195-208.

Graves, D., \& Sheldon, J. P. (2018). Recruiting African American children for research: An ecological systems theory approach. Western journal of nursing research, 40(10), 1489-1521.
Hammarberg, K., Kirkman, M., \& de Lacey, S. (2016). Qualitative research methods: when to use them and how to judge them. Human reproduction, 31(3), 498-501.

Lestari, D. J., \& Putra, A. P. (2019, May). Makna Simbolik Kakawihan Barudak Banten: Cing Ciripit Sebagai Penguatan Karakter Dalam Tindakan, Motif, Dan Prinsip Ekonomi. In Prosiding Seminar Nasional Pendidikan FKIP (Vol. 2, No. 1, pp. 769-773).

Lestari, G. (2015). Bbineka Tunggal Ika: Khasanah Multikultural Indonesia di Tengah Kehidupan Sara. Jurnal Pendidikan Pancasila dan Kewarganegaraan, 28 (1), 31-37.

Mayakania, N.D. (2013). Internalisasi NilaiNilai Pendidikan Karakter melalui Kakawihan Kaulinan Barudak Bubun di Komunitas 'Hong' Bandung. (2013). Panggung, 23(4), 443-455.

-------. (2016). Penerapan Ajen Atikan untuk Anak-Anak Komunitas Hong melalui Seni Kakawihan Kaulinan Barudak Bubun dalam Upaya Membinan Kesalehan Budaya. Jurnal Sosioreligi, 14(1), 46-50.

Moleong, L. (1988). Metode Penelitian Kualitatif. Ohio: PT Remaja Rosdakarya Bandung.

Morrison, J. W., Storey, P., \& Zhang, C. (2011). Accessible family involvement in early childhood programs. Dimensions of Early Childhood, 39(3), 21-26.

Santrok, J.W. (2007). Perkembangan Anak Edisi Kesebelas Jilid 2. Jakarta: Erlangga.

Sardjunani, N. (2006). Studi Kebijakan Pengembangan Anak Usia Dini yang Holistik dan Terintegerasi. Jakarta: BAPPENAS.

Satori, D., \& Komariah, A. (2009). Metodologi Penelitian Kualitatif. Bandung: Alfabeta.

Sutton, J., \& Zubin, A. (2015). Qualitative Research: Data Collection, Analysis, and Management. The Canadian Journal of Hospital Pharmacy, 68(3), 226-231.

Tondo, H. (2009). Kepunahan bahasa-bahasa daerah: faktor penyebab dan implikasi etnolinguistis. Jurnal masyarakat dan budaya, 11(2), 277-296. 